\title{
Hybrid Deep Eutectic Solvent of LiTFSI-Ethylene Glycol Organic Electrolyte for Activated Carbon-Based Supercapacitors
}

\author{
Kieu T. Tran, ${ }^{1}$ Tuyen T. T. Truong, ${ }^{1}$ Hoang V. Nguyen $\mathbb{D}^{1,2}$ Quan D. Nguyen, ${ }^{2,3}$ \\ Quan Phung, ${ }^{2,4}$ Phung M. L. Le $\mathbb{D}^{1,2,4}$ and Man V. Tran $\mathbb{D}^{1,2,4}$ \\ ${ }^{1}$ Applied Physical Chemistry Laboratory (APCLAB), VNUHCM-University of Science, Ho Chi Minh City, Vietnam \\ ${ }^{2}$ Viet Nam National University Ho Chi Minh City (VNUHCM), Ho Chi Minh City, Vietnam \\ ${ }^{3}$ Biofuel and Biomass Research Laboratory, Faculty of Chemical Engineering, University of Technology (HCMUT), \\ Vietnam National University (VNUHCM), Ho Chi Minh City, Vietnam \\ ${ }^{4}$ Department of Physical Chemistry, VNUHCM-University of Science (HCMUS), Ho Chi Minh City, Vietnam
}

Correspondence should be addressed to Phung M. L. Le; lmlphung@hcmus.edu.vn

Received 21 March 2021; Revised 11 September 2021; Accepted 14 September 2021; Published 5 October 2021

Academic Editor: Shahid Hussain

Copyright (c) $2021 \mathrm{Kieu}$ T. Tran et al. This is an open access article distributed under the Creative Commons Attribution License, which permits unrestricted use, distribution, and reproduction in any medium, provided the original work is properly cited.

\begin{abstract}
This research work demonstrates a novel hybrid electrolyte based on a deep eutectic solvent (DES) combined with organic solvents for high-performance supercapacitors. DES was formed between ethylene glycol (EG) and lithium bis((trifluoromethyl)sulfonyl) imide (LiTFSI) and diluted by ethylene carbonate (EC) or acetonitrile (AN) with different amounts (10-50\% wt.). Such a combination gives superior properties for hybrid electrolytes compared to pure DESs and reduces the volatility of mixed organic solvents. Regarding the electrochemical properties, DES-AN mixtures exhibited a better performance under high applied voltage and more reversible behavior than DES-EC ones, which suffered from the increasing distance in the electrical double layer. DES $1:$ $4+20 \%$ wt. AN exhibited favorable electrolyte properties such as high ionic conductivity $\left(3.1 \mathrm{mS} \cdot \mathrm{cm}^{-1}\right.$ at $\left.30^{\circ} \mathrm{C}\right)$, relatively lower viscosity $\left(14.28 \mathrm{mPa}\right.$ at $30^{\circ} \mathrm{C}$, approximately 2 times lower thanDES pure), and quite large electrochemical stability window up to $3.4 \mathrm{~V}$ (at 20-30\% wt. AN) compared to the baseline electrolyte (LiTFSI/TBABF 4 in AN). With these interesting properties, selected hybrid electrolyte (DES 1:4+20\% wt. AN) tested in the symmetric capacitor using the activated carbon offered decent capacitance

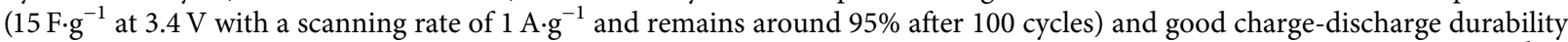
( $>80 \%$ retention after 2000 cycles), especially the EDLC with DES $1: 4+20 \%$ wt. AN shows good rate capacity $\left(13.2 \mathrm{~F} \cdot \mathrm{g}^{-1}\right.$ at $2 \mathrm{~A} \cdot \mathrm{g}^{-1}$, remaining $6 \mathrm{~F} \cdot \mathrm{g}^{-1}$ at $\left.10 \mathrm{~A} \cdot \mathrm{g}^{-1}\right)$.
\end{abstract}

\section{Introduction}

Energy shortages and environmental pollution induced by heavy fossil fuel usage have inspired researchers to seek alternative sustainable energy to fossil forms such as wind and solar energy [1]. High-power energy storage devices are required for high and strong altitudes of wind turbine pitch regulation or for maximizing the intermittent use of solar power as power sources for cold-cranking gasoline engines [2-4]. Supercapacitors, also known as ultracapacitors or electrochemical condensers, store electrical charges through an electronic double layer at the interface of carbon electrode-electrolyte, which are needed to smoothly integrate renewable energy output into the grid [5]. In the electric double layer capacitor (EDLC) system, electrostatic adsorption of electrolyte ions occurs at the interface between electrode and electrolyte, thereby achieving rapid charge/ discharge cycle, and increases stability though their real potential and energy density which are comparatively lower [6]. The efficiency of supercapacitors is highly affected by the physical and chemical properties of the electrode materials and electrolytes adopted [7]. Thus, the production of highperformance electrode materials, as well as the stable electrolyte, is the fundamental prerequisite for supercapacitor design. The conventional electrolyte of the supercapacitor consists of organic solvents (usually AN) and alkylammonium salt. Although these mixtures have strong conductivity and ion transport properties, they also have high volatility, 
flammability, and toxicity leading to safety and environmental concerns [8]. The choice of the electrolyte is therefore very influential.

In recent years, various materials have been studied for supercapacitor applications such as conduction polymers, carbonaceous material, metal oxides, and metal chalcogenides [9]. Among them, high-performance supercapacitor was studied by using many transition metal oxides as electrode material such as $\mathrm{NiCo}_{2} \mathrm{~S}_{4}$ [10], $\mathrm{MoS}_{2}$ [11], $\mathrm{Mn}_{3} \mathrm{O}_{4}$ [12], $\mathrm{CoMoO}_{4}$ [13], 3D $\mathrm{MnO}_{2}$ nanorod [14], and $\mathrm{NiFe}_{2} \mathrm{O}_{4}-$ NP-NS@CC [15] due to their low cost, high theoretical capacity, and environment friendly characteristics. Besides this, the research of nonflammable electrolyte systems for $\mathrm{Li}$ metal batteries and supercapacitor has been dedicated to significant efforts. These include all-solid-state and quasisolid-state electrolytes [16], all-fluorinated-based electrolytes [17], ionic liquid-based electrolytes [18], and deep eutectic solvents (DESs) [19-21]. Among them, DESs have been greatly paid attention to replace carbonate solvents, which are of particular interest owing to their numerous advantages such as low vapor pressure, nonflammability, biodegradability, low cost, and ease of preparation [21]. Hence, DESs serve as powerful electrolytes for supercapacitors.

Despite the substantial advantages, the practical applications of DESs are being hindered by their very high viscosity, which leads to very low conductivity and poor capacitance in comparison with the conventional. Typically, DESs based on a combination of N-methyl acetamide and $\mathrm{LiNO}_{3}$ demonstrated a low conductivity of around $1.0 \mathrm{mS} \cdot \mathrm{cm}^{-1}$ at $25^{\circ} \mathrm{C}$ [19], which is significantly lower than the typical value $\left(50 \mathrm{mS} \cdot \mathrm{cm}^{-1}\right)$ for organic electrolytes. On the other hand, Le et al. [22] stated that the introduction of organic solvents could improve the ionic conductivity of ionic liquids and their cycling performance in lithium-ion batteries. Therefore, mixtures of DESs and organic solvents could also be investigated to achieve superior electrolyte performance.

In prior work, low-temperature DESs were reported to be formulated at a molar ratio of $1: 4$ of the starting precursors, for example, DESs based on N-methyl acetamide (MAc) and lithium bis((trifluoromethyl)sulfonyl) imide (LiTFSI) [15]. Similarly, DESs with the combination of $\mathrm{N}$-methyl acetamide (MAc) and lithium salts [16] were mostly in the liquid state at ambient temperature in the case of mole fraction $x_{L i+}=0.25$. Herein, to be practically applied in EDLC using activated carbon, hybrid electrolytes based on DES mixed with \%wt. solvent (ethylene carbonate or acetonitrile) were investigated. The pure DES at a molar ratio of $1: 4$ between lithium bis((trifluoromethyl)sulfonyl) imide (LiTFSI) and ethylene glycol (EG) was selected to combine with the solvent owing to its lowest viscosity and highest ionic conductivity, as previously reported in our study [23].

\section{Experimental}

2.1. DESs and DES-Based Electrolytes Preparation. Lithium bis((trifluoromethyl)sulfonyl) imide (LiTFSI, 99,9\%), ethylene glycol (EG, >99\%), tetrabutylammonium tetrafluoroborate $\left(\mathrm{TBABF}_{4},>99 \%\right)$ ethylene carbonate (EC, $>98 \%$ ), acetonitrile (AN, >98\%), N-methyl-2-pyrrolidone (NMP, >99\%), and poly(vinylidene fluoride-co-hexafluoropropylene) (PVDF-HFP, 99\%) were purchased from Sigma-Aldrich and stored in the glove box with the content of both water and oxygen below $1 \mathrm{ppm}$.

The mixture of $20 \%$ wt. LiTFSI and $80 \%$ wt. EG was stirred at $80^{\circ} \mathrm{C}$ for at least 8 hours to give a homogeneous DES (DES 1:4). DES 1:4 has been proved as the potential DES compromising the ionic conductivity $[23,24]$. Indeed, the low amount of LiTFSI induces a better dissociation of ions and low viscosity of DES fluid. Hence, DES 1:4 was dissolved with an appropriate amount of either EC or AN $(10-50 \%$ wt.) to obtain hybrid DES-based electrolytes for supercapacitor testing.

2.2. Preparation of Electrodes and Cell Assembly. The electrodes were prepared by coalescing activated carbon (TRABACO, Vietnam) and PVDF-HFP in NMP $(50 \mathrm{mg} /$ $\mathrm{mL}$ ) in a weight ratio of $95: 5$. The wet slurry was coated onto technical $\mathrm{Ni}$ foil and dried in a vacuum oven at $80^{\circ} \mathrm{C}$ for 15 hours and then cut into $14 \mathrm{~mm}$ diameter round plates.

Symmetric supercapacitors were assembled in the glovebox using coin cell CR2032 consisted of the as-prepared electrodes, glass microfiber separator (Whatman, GF/C), and DES-based electrolytes.

2.3. Characterization Techniques. Infrared spectroscopy (IR) was used to verify whether the DES configuration was affected by additional organic solvents. The experiments were conducted in the wavenumber range of $500 \mathrm{~cm}^{-1}-4000 \mathrm{~cm}^{-1}$ on an FT/IR-6600 spectrometer. The reflected light was detected by triglycine sulfate (TGS). After triangular apodization, the spectral resolution and scanning rates were $8 \mathrm{~cm}^{-1}$ and $2 \mathrm{~mm} \cdot \mathrm{s}^{-1}$, respectively.

The thermal behavior of electrolytes was assessed by thermogravimetric analysis (TGA) using a LABSYS Evo instrument. All the measurements were performed under nitrogen atmosphere from $25^{\circ} \mathrm{C}$ to $600^{\circ} \mathrm{C}$ with the heating step of $10^{\circ} \mathrm{C} \cdot \mathrm{min}^{-1}$.

The self-extinguishing time (SET) and flash time (FT) were recorded to confirm the flammability of the electrolytes. Concerning the SET experiments, glass fibers soaked into the electrolytes with a weight of approximately $100 \mathrm{mg}$ were exposed to the ignition source at a fixed distance of $13 \mathrm{~cm}$. The ignition source was kept on for 3 seconds. The time required to extinguish the flame after that was recorded as $\operatorname{SET}\left(\mathrm{s} \cdot \mathrm{g}^{-1}\right)$. The FT is referred to as the lowest time, whereas a sample can be burned under defined conditions. The distance between the sample and burner in the FT test is $20 \mathrm{~cm}$. The FT value $\left(\mathrm{s} \cdot \mathrm{g}^{-1}\right)$ was recorded instantly when the electrolyte flashes fire.

Ionic conductivity of the prepared electrolytes was calculated as the inverse of resistance that is measured by AC impedance spectroscopy in the frequency range of $1 \mathrm{MHz}-100 \mathrm{MHz}$ at room temperature. The experiments were performed on VSP 1320 device (Biologic, France). The cell constant was calibrated by using $0.100 \mathrm{M} \mathrm{KCl}$ solution. 
Viscosity measurement of DES-based electrolytes was carried out in the glovebox at ambient temperature using an Ostwald viscometer. The standard volume for viscosity measurement is $4 \mathrm{~mL}$.

Cyclic voltammetry (CV) is the common method to estimate the electrochemical stability of DES-based electrolytes. A three-electrode cell was used for CV measurement, including a nickel counterelectrode, a platinum working electrode, and a silver wire dipped in a solution of $10 \mathrm{mM} \mathrm{AgNO}_{3}$ in acetonitrile $+0.1 \mathrm{M}$ tetrabutylammonium perchlorate (TBAP) as the reference electrode. The measurement was conducted on an MPG2 unit (Biologic, France). The electrochemical kinetic of EDLC was also performed by the $\mathrm{CV}$ test by observing the typical featuring curve.

The morphology and the dimension distribution of activated carbon were determined by scanning electron microscopy (SEM) on Hitachi SU8000. Also, subcritical $\mathrm{N}_{2}$ gas adsorption at liquid nitrogen temperature $(77 \mathrm{~K})$ is used for characterizing the surface area and pore structure of the electrode material. The experiments were conducted on Nova Station A instrument.

$\mathrm{X}$-ray photoelectron spectroscopy (XPS) investigations were performed using an AXIS-NOVA (Kratos) spectrometer equipped with a monochromated $\mathrm{Al} \mathrm{K} \mathrm{X-ray}$ source $(\mathrm{hv}=1486.6 \mathrm{eV})$ operating at $150 \mathrm{~W}$ and a base pressure of 2.6109 Torr.

The structure of the activated carbon was determined using an X-ray diffraction (XRD) pattern acquired in a D8 ADVANCED (Brucker) diffractometer utilizing $\mathrm{CuK}$ radiation $(\lambda=1.5814 \AA)$ operated at a scanning rate of $0.02^{\circ} / \mathrm{step} /$ $1 \mathrm{~s}$ between $10^{\circ}$ and $70^{\circ} 2 \theta$.

Cycling performance of symmetric supercapacitors was obtained by Galvanostatic cycling with potential limitation (GCPL) using an MGP2 system. The charge/discharge processes were evaluated in the voltage range of $-1.7-1.7 \mathrm{~V}$ at $1,2,5$, and $10 \mathrm{~A} \cdot \mathrm{g}^{-1}$ rate.

Electrochemical impedance spectroscopy (EIS) of the capacitors was measured around the open-circuit voltage (OCV) with a $10 \mathrm{mV}$ sinusoidal signal over the frequency range from $1 \mathrm{MHz}$ to $1 \mathrm{kHz}$ for supercapacitor before and after long cycling performance.

\section{Results and Discussion}

Tran et al. [23] established the formation of DES by new hydrogen bonding from precursor components (LiTFSI and EC) using IR spectroscopy which is similar to our experimental work. This research claimed that the broad $\mathrm{OH}$ stretching peak of EG, $v\left(\mathrm{OH}\right.$ ), shifted from $3292 \mathrm{~cm}^{-1}$ (EG pure) to $3313 \mathrm{~cm}^{-1}$ (DES 1:4) indicating the formation of new hydrogen bonds for the DES LiTFSI : EG $(1: 4)$.

In Figure 1, IR spectra including synthesized DESs, organic solvent (AN, EC), pure LiTFSI, and precursors EG were analyzed. When combining with the amount of solvent, the change in the DES configuration could also be observed through the wavenumber shifting of vibration modes. It means that the more the organic solvent is added, the more the intermolecular hydrogen bonds are weakened or even broken due to the dilution phenomena. However, the vibration band of free $\mathrm{O}-\mathrm{H}\left(3500 \mathrm{~cm}^{-1}\right)$ might be much stronger than the shifting observation. Additionally, the $\mathrm{O}-\mathrm{H}$ vibrations were hardly observed in a high range of frequencies $[25,26]$. However, as the content of organic solvents ( $\leq 20 \% \mathrm{wt}$.) is low, the enlargement of the vibrational band is negligible suggesting that the DES configuration may not be affected.

IR spectra of pure AN exhibits the minor peak at around $2250 \mathrm{~cm}^{-1}$ attributed to the stretching vibration of $\mathrm{C} \equiv \mathrm{N}$ [27]. However, this assignment disappears in all IR spectra of DES-AN mixtures. This is presumably due to the relatively low AN content in the mixture with DES 1:4. Indeed, the infrared band intensity of AN decreased remarkably at the liquid phase compared to the gaseous phase [27]. It means that this specific assignment could be only observed in the IR spectra when the concentration of AN molecules in the vapor phase is as much as in the pure liquid one.

According to Table 1, DES-AN mixtures exhibited a much lower temperature range of weight loss than their DES-EC counterparts (practically $100^{\circ} \mathrm{C}$ for the difference). DES-EC mixtures also experienced two periods of weight loss despite the presence of three components in these mixtures (Figure 2). It could be explained by the low difference of boiling points between EG and EC, leading to the overlapped evaporation in the first stage of weight loss ( $T_{b}$ of EG and EC are $212^{\circ} \mathrm{C}$ and $251^{\circ} \mathrm{C}$, respectively).

Regarding DES-AN miscible electrolytes, there is no obvious transition between the first and second steps. Accordingly, once AN molecules evaporate, they tend to pull out EG molecules loosely bonded in the mixture for simultaneous evaporation. Indeed, the boiling point of EG reduces when the AN proportion of the mixed electrolyte increases $\left(1^{\text {st }}\right.$ weight loss temperature decreases). Therefore, the addition of a third component having a lower boiling point than the other components tends to lower this point of the whole miscible solution, but in turn, elevate its boiling temperature compared to the value of its pure state [28]. Likewise, in DES-EC mixtures, the increase of the first weight loss temperature was also observed when increasing the EC component content (which has a higher boiling point, about $251^{\circ} \mathrm{C}$ than the EG component).

Unexpectedly, the addition of organic solvent slightly penalizes the thermal stability of DES-based electrolytes, as indicated by the increase of SET values along with the content of added solvent (Table 2). Likely, the combustion of DES was triggered by igniting either AN or EC vapors [29-31]. As the more volatile organic solvents are added, their high partial vapor pressure eventually inclined their flammability. Also, both AN and EC being flammable may exhibit intense combustion and release heat. Furthermore, the heat release effectively triggered the flame reaction of DES which is mainly responsible for the prolonged SET of these mixtures. In comparison with $\mathrm{AN}$, EC has relatively lower vapor pressure due to its high boiling point $\left(\sim 250^{\circ} \mathrm{C}\right)$ and high flash point $\left(145^{\circ} \mathrm{C}\right)[29,32]$. As a result, the SET values of DES-EC mixtures are not smaller than those of DES-AN ones. Based on our investigated results, the percentage of volatile organic solvents in the DES 1:4 mixture 


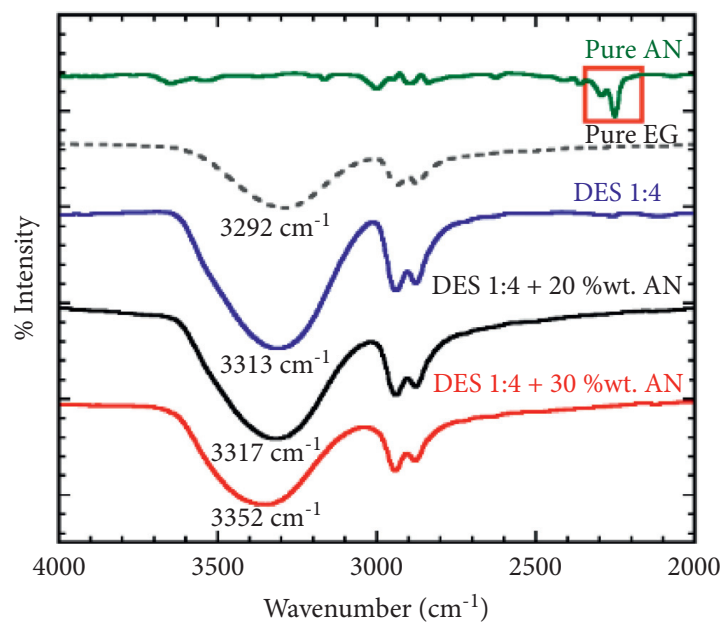

(a)

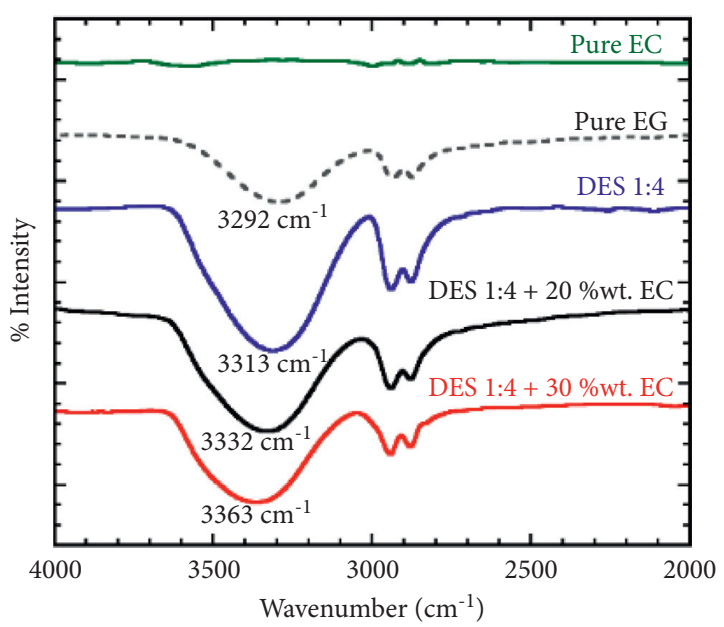

(b)

FIGURE 1: IR spectra of DES-organic solvent mixtures with different amounts of acetonitrile (a) or ethylene carbonate (b).

TABLE 1: The onset temperatures $\left(T_{d}\right)$ corresponding to the stages of weight loss of DES-based electrolytes.

\begin{tabular}{lcc}
\hline Mixture & $\mathrm{T}_{\text {onset }}\left({ }^{\circ} \mathrm{C}\right)$ & Weight loss $(\%)$ \\
\hline Pure AN & 85.0 & 81.3 \\
Pure EC & 251 & 99.5 \\
DES $1: 4$ & $220 / 478$ & $79.2 / 17.6$ \\
DES $1: 4+10 \%$ wt. AN & $109 / 214 / 436$ & $12.3 / 62.0 / 10.0$ \\
DES $1: 4+20 \%$ wt. AN & $108 / 207 / 438$ & $13.4 / 59.5 / 13.7$ \\
DES $1: 4+30 \%$ wt. AN & $95 / 196 / 416$ & $14.5 / 56.8 / 13.1$ \\
DES $1: 4+10 \%$ wt. EC & $204 / 417$ & $75.9 / 16.9$ \\
DES $1: 4+20 \%$ wt. EC & $214 / 441$ & $84.8 / 13.8$ \\
DES $1: 4+30 \%$ wt. EC & $214 / 433$ & $85.7 / 10.5$ \\
\hline
\end{tabular}

should be maintained at below $30 \%$ wt. to prevent the negative effect on the electrolyte flammability.

As known, the introduction of organic solvent lowered the viscosity and consequently improved the conductivity of DES-based electrolytes compared to pure DES solution. Evidently, in Table 2, the mixtures of DES 1:4 with EC exhibited higher ionic conductivities than DES-AN counterparts even at $50 \% \mathrm{wt}$. despite the relatively higher viscosity of EC $\left(1.93 \mathrm{cP}\right.$ at $40^{\circ} \mathrm{C}$ [33]) compared to the acetonitrile solvent $\left(0.335 \mathrm{cP}\right.$ at $\left.25^{\circ} \mathrm{C}\right)$. It could be explained by the higher dielectric constant $(\square)$ of EC, which helps to dissociate the lithium salt better or, to be more precise, solvate lithium salts more effectively than $A N\left(\square_{E C}=90\right.$ and $\square_{A N}=36$ at $298 \mathrm{~K}$ ) [34]

The choice and the content of additive solvents were considered as determinant factors for enhancing the rate performance and the remaining intrinsic properties of DESbased hybrid electrolyte. Figure 3 compares the anodic and cathodic potential limits of DES 1:4 mixed with different amounts of two different organic solvents. Expectedly, the solvent addition enhances the oxidation stability although the reduction limit slightly decreased. As a result, the electrochemical window was enlarged with the addition of certain solvent contents. It seems that the mixtures with 20-30\% wt. cosolvent (EC or AN) demonstrated the best electrochemical stability, that is, the highest oxidation potential and lowest reduction potential (see Table 3 ).
Electrical double-layer capacitor (EDLC) using activated carbon (AC) was performed to study the electrochemical behavior of DES-based hybrid electrolytes. Activated carbon (AC) prepared from granular coconut shell charcoal by steam activation at high temperature exhibits an amorphous shape with a wide range of particle sizes from 0.2 to $2 \mu \mathrm{m}$ (Figure 4). AC exhibits small mesopores (2-3 nm) associated with large micropores. The micromesopores of AC material are essentially required to enhance electrolyte accessibility and retention. The morphology of the AC-based electrode remained virtually unchanged after mixing with $\mathrm{PVdF}$ binder in N-methyl pyrrolidone solvent and deposited onto $\mathrm{Ni}$ foil, which proves that the porous structure of this electrode remains as such (Figure 4).

X-ray diffraction (XRD) pattern for activated carbon shown in Figure 5 displays the main peak of AC is situated at $26.35^{\circ}(002)$, and other smaller signal is situated at $42.6^{\circ}$ (100) and $44.8^{\circ}$ (101) respectively, conforming to diffraction data of carbon material (JCPDS no. 00-001-0640).

The chemical compositions of activated carbon were further analyzed by XPS, the results are shown in Figure 6, and the surface atomic composition is presented in Table 4. Figure 6(a) depicts the XPS survey spectrum of activated carbon, showing the presence of carbon, oxygen, chloride, sulfur, and silica. The contents of $\mathrm{C}$ atomic are obviously maximum (around 93.22\%), confirming that the sample has good purity. Additionally, high $\mathrm{O}$ content could be 


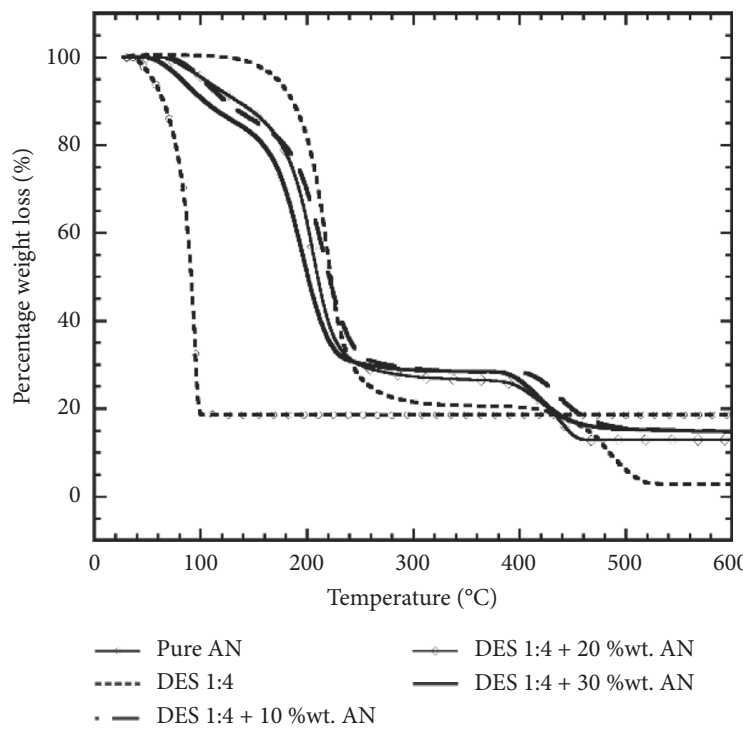

(a)

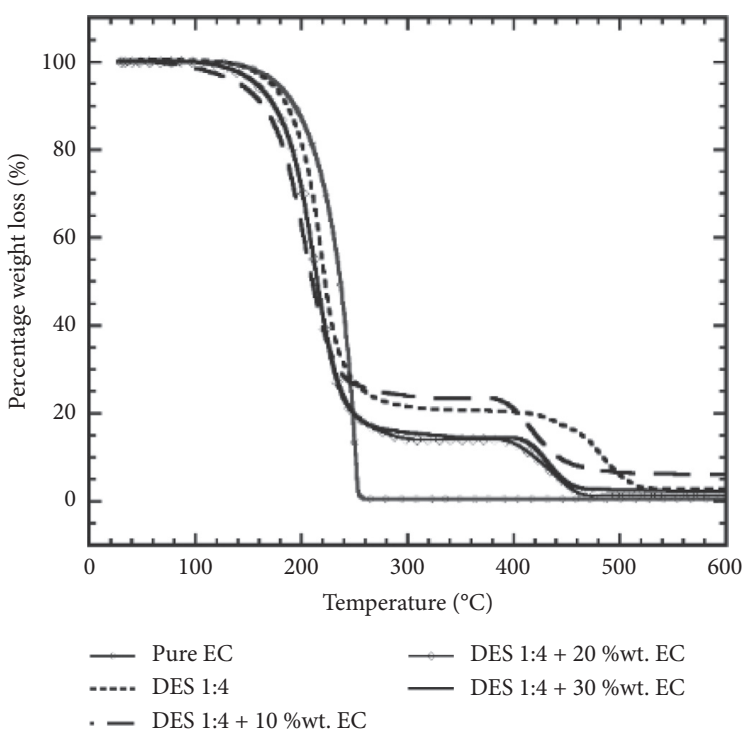

(b)

Figure 2: Thermogravimetric curves of DES-AN (a) and DES-EC-based electrolytes (b).

TABLE 2: Density, viscosity, ionic conductivity, and self-extinguishing time (SET) of DESs and mixtures of DES $+x \%$ wt. AN (or EC) at room temperature.

\begin{tabular}{|c|c|c|c|c|}
\hline Mixture & Density $\left(\mathrm{g} \cdot \mathrm{cm}^{-3}\right)$ & Viscosity $(\mathrm{mPa} \cdot \mathrm{s})$ & Conductivity $\left(\mathrm{mS} \cdot \mathrm{cm}^{-1}\right)$ & SET $\left(s \cdot g^{-1}\right)$ \\
\hline DES $1: 4$ & 1.203 & 21.80 & 2.98 & 50.6 \\
\hline DES $1: 4+10 \%$ wt. AN & 1.143 & 18.38 & - & 55.8 \\
\hline DES $1: 4+20 \%$ wt. AN & 1.089 & 14.28 & 3.06 & 52.4 \\
\hline DES $1: 4+30 \%$ wt. AN & 1.038 & 12.74 & - & 56.9 \\
\hline DES $1: 4+40 \%$ wt. AN & 0.993 & 10.19 & - & 67.8 \\
\hline DES $1: 4+50 \%$ wt. AN & 0.943 & 9.47 & 3.12 & 68.2 \\
\hline DES $1: 4+10 \%$ wt. EC & 1.220 & 20.35 & - & 52.3 \\
\hline DES $1: 4+20 \%$ wt. EC & 1.225 & 17.66 & 3.33 & 54.0 \\
\hline DES $1: 4+30 \%$ wt. EC & 1.236 & 15.42 & - & 56.1 \\
\hline DES $1: 4+40 \%$ wt. EC & 1.248 & 13.22 & - & 59.9 \\
\hline DES $1: 4+50 \%$ wt. EC & 1.260 & 12.37 & 4.23 & 60.3 \\
\hline
\end{tabular}

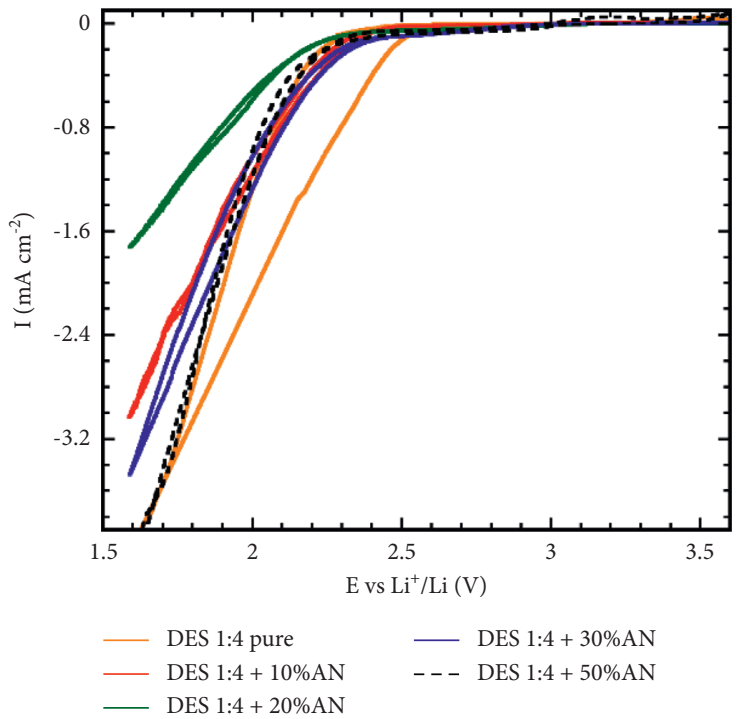

(a)

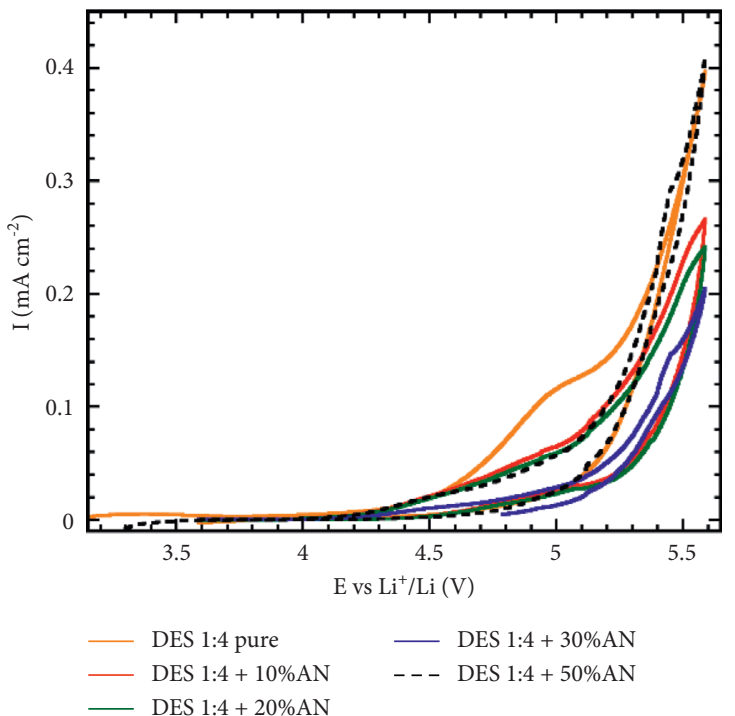

(b)

FIGURE 3: Continued. 


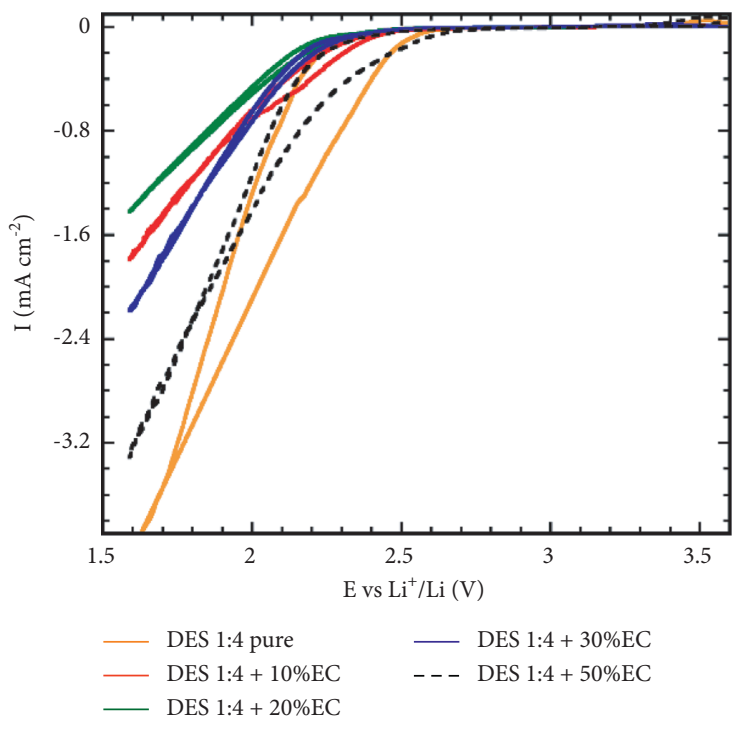

(c)

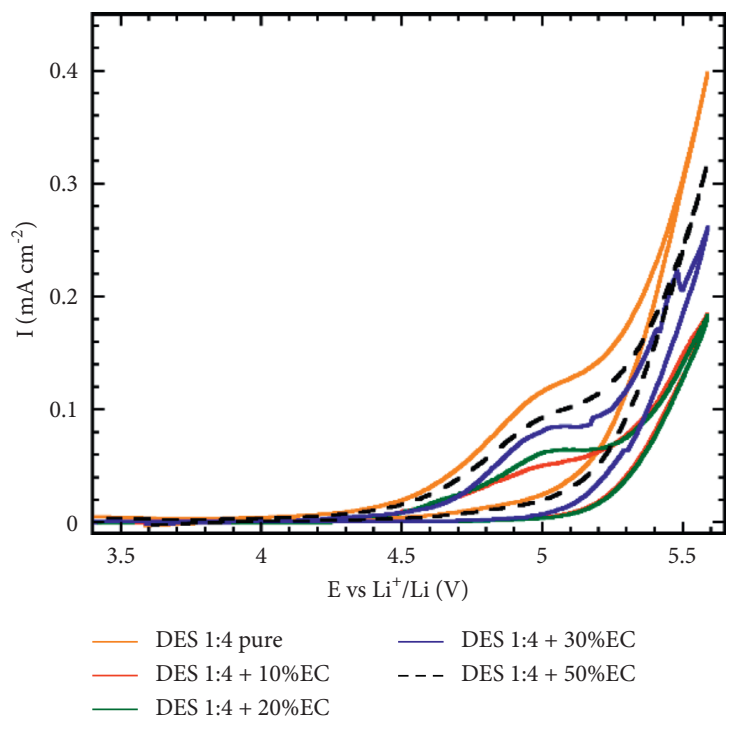

(d)

Figure 3: CV curves representing the oxidation $(b, d)$ and reduction $(a, c)$ limit of DES-based electrolytes.

TABLE 3: Oxidation and reduction limit potentials of mixture DES $1: 4+x \%$ wt. AN and DES $1: 4+y \%$ wt. EC.

\begin{tabular}{lccccc}
\hline$x(\%)$ & $\mathrm{E}_{\text {anode }}(\mathrm{V})$ & $\mathrm{E}_{\text {cathode }}(\mathrm{V})$ & $y$ & $\mathrm{E}_{\text {anode }}(\mathrm{V})$ & $\mathrm{E}_{\text {cathode }}(\mathrm{V})$ \\
\hline $0 \%$ wt. AN & 4.52 & 2.55 & $0 \%$ wt. EC & 4.52 & 2.55 \\
$10 \%$ wt. AN & 4.55 & 2.43 & $10 \%$ wt. EC & 4.66 & 2.42 \\
$20 \%$ wt. AN & 4.58 & 2.42 & $20 \%$ wt. EC & 4.65 & 2.42 \\
$30 \%$ wt. AN & 4.58 & 2.64 & $30 \%$ wt. EC & 4.67 & 2.41 \\
$50 \%$ wt. AN & 4.49 & 2.73 & $50 \%$ wt. EC & 4.55 & 2.41 \\
\hline
\end{tabular}

${ }^{*} i_{\text {background }}$ for $E_{\text {cathode }}=0.02 \mathrm{~mA}, \mathrm{i}_{\text {background }}$ for $E_{\text {anode }}=0.002 \mathrm{~mA} .{ }^{*}$ : the potential value is versus $\mathrm{Li}^{+} / \mathrm{Li}$.

associated with metal oxides besides nonmetal elements. The principal $\mathrm{C}$ 1s peak could be contributed to more than one type of carbon. As shown in Figure 6(b), peaks located at a binding energy of 288 and $285 \mathrm{eV}$ correspond to the functional groups of $\mathrm{C}=\mathrm{O}$ and $\mathrm{C}-\mathrm{C}$ [35], respectively. Furthermore, the proportions of $\mathrm{C}=\mathrm{O}$ and $\mathrm{C}-\mathrm{C}$ are $31.84 \%$ and $68.52 \%$, respectively.

When adding EC or AN solvent into the neat DES 1:4, the area of deformed rectangular shape is enlarged at $\Delta E=3.2 \mathrm{~V}$ (Figures 5(a) and 5(b)). The results are consistent with the ionic conductivity of all DES-derived electrolytes (Table 2). In addition, CV curves of activated carbon-based symmetric cells using $\mathrm{AN}+1 \mathrm{M} \mathrm{TBABF}_{4}$ and $\mathrm{AN}+1 \mathrm{M}$ LiTFSI (conventional electrolyte) were also recorded at a similar scan rate (Figures 5(c) and 5(d)) for comparison. In detail, the former exhibits the distorted rectangular shape and becomes an asymmetric curve with long sloping curvature even at the low applied potential $(<3.0 \mathrm{~V})$. Moreover, the potential limit of the LiTFSI-AN system seems to be lower than $3.2 \mathrm{~V}$ due to the organic solvent oxidation (recognized by the sharp edge) although it exposes a quite perfect CV curve at $\Delta E=3.0 \mathrm{~V}$.

Figure 7 provides the $\mathrm{CV}$ curves of the two-electrode symmetric coin-cell assembled with two AC-based electrodes and DES-based electrolytes recorded at various applied voltages. Specific capacitance $C_{s}$ value is calculated according to the equation: $C_{s}=I /(\Delta \mathrm{V} \cdot \mathrm{m} / \Delta t)$ [36] (shown in Table 5). The specific capacitance increases with the applied voltage due to the elevation of charge accumulation on the surface. For each mixed electrolyte, CV scan was performed for 100 cycles at different potential limits, whereas the capacitance loss is over 5\% (indicating remarkably performance decline or supercapacitors).

In DES-EC mixed electrolyte, a slightly higher capacitance compared to the DES-AN system is presumably explained by its higher conductivity (Table 2). For instance, at $\Delta E=3.2 \mathrm{~V}$, the capacitance of supercapacitor containing $20 \%$ wt. AN or EC is about 15.23 and $15.67 \mathrm{~F} \cdot \mathrm{g}^{-1}$, respectively However, the DES-AN system used as EDLC electrolyte reveals a beautifully ideal rectangular shape, indicating better reversibility during the charge/discharge process.

Regarding DES 1:4+10\% wt. AN, when charged up to $3.0 \mathrm{~V}$, the capacitance considerably reduced. However, this phenomenon is less pronounced for $20-30 \%$ AN added in DES, and the capacitance retention after 100 cycles is higher than $95 \%$ even at $\Delta E=3.4 \mathrm{~V}$. Additionally, the $Q_{\text {charge }} / Q_{\text {discharge }}$ ratios of those systems shown in Table 5 are higher than $99.5 \%$ at all applied voltage values. Unfortunately, the stability of capacitance cannot be maintained when the voltage range $(\Delta \mathrm{E})$ exceeds $3.4 \mathrm{~V}$ at $\Delta E=3.6 \mathrm{~V}$. As a result, the retention after 100 cycles is 


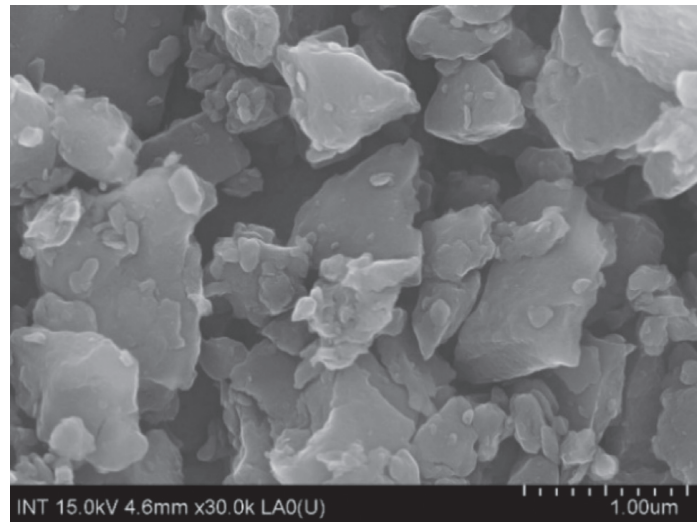

(a)

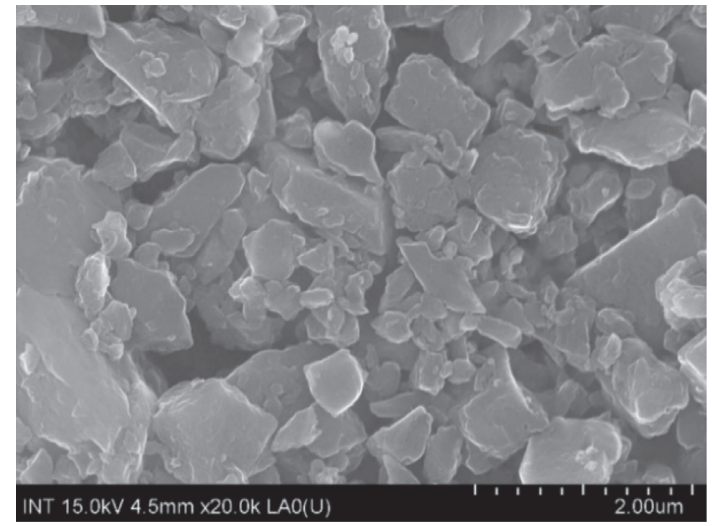

(b)

FIgure 4: SEM images of AC powder (a) and AC-based electrode (b).

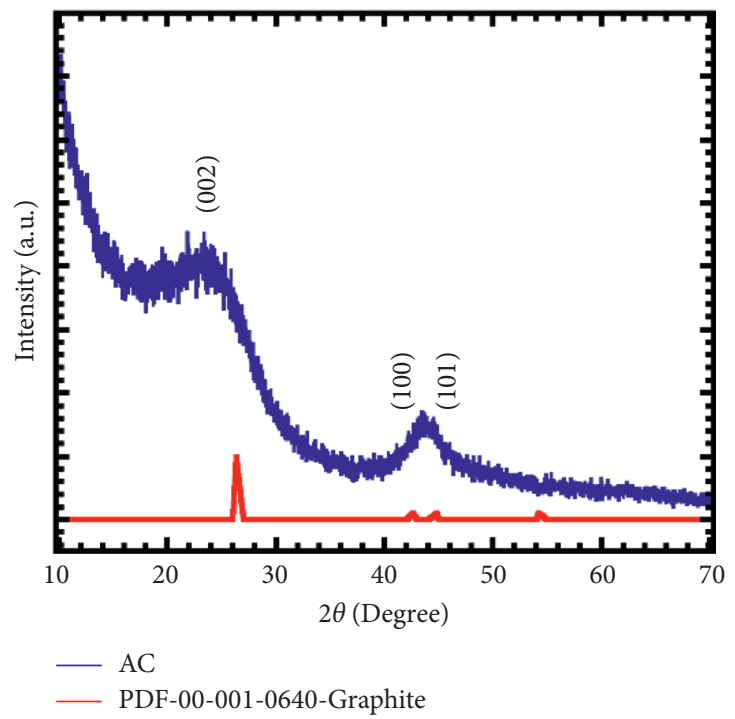

FIgure 5: Powder XRD pattern of AC.

approximately $90 \%$ for both electrolytes. In brief, DES 1 : $4+20-30 \%$ wt. AN can withstand the applied potential window of up to $3.4 \mathrm{~V}$, which is much wider than that of aqueous electrolytes (below $2.0 \mathrm{~V}$ ).

On the contrary, DES-EC mixed electrolyte showed a distorted rectangular shape with two "sharp" edges. This nonideality could be attributed to the participation of EC molecules in the formation of an electrical double layer (EDL). Due to the very good solvation ability of EC, the desolvation of $\mathrm{Li}^{+}$at the electrode surface is less efficient, resulting in the coadsorption of its EC-rich solvent sheath. When the EC content is up to $20 \%$ wt., the average distance between the carbon wall and the ion center may be considerably increased, consequently leading to the capacitance decrease according to the equation: $\mathrm{C}=\square A / d$ (where $A$ is the surface area, $d$ is the distance between carbon and ions, and $\square$ is the local dielectric constant of the electrolyte). Besides this, the relatively high viscosity of DES-EC mixtures compared to DES-AN ones may additionally increase the distance between the carbon and solvated ions.
Considering the good electrochemical behavior as well as physicochemical properties, DES with $20 \%$ wt. AN and $30 \%$ wt. AN was continuously tested for a long cycling performance at the operating potential window of $3.4 \mathrm{~V}$.

As shown in Figures 8(a) and 8(b), the specific capacitance of both systems dramatically decreases at high scan rates (detailed values in Table 6). This might be due to their ionic transport limitation linked to the high viscosity. In particular, the interfacial double layer formation originated from ion diffusion is not dense enough at fast scanning speed to avoid capacity loss.

In the DES 1:4+20\% wt. AN system, the capacitance vs. cycle number showed an anomalous tendency (Figure 9(a)). The capacitance steadily increases in the first 500 cycles to reach the highest point of $15.3 \mathrm{~F} \cdot \mathrm{g}^{-1}$ and then decreases to $11.5 \mathrm{~F} \cdot \mathrm{g}^{-1}$ at the $2000^{\text {th }}$ cycle and $9.2 \mathrm{~F} \cdot \mathrm{g}^{-1}$ at the $5000^{\text {th }}$ cycle. This strange tendency could be explained by the sluggish transportation of ions into/out of micropores of the active material related to the high viscosity of DES-based hybrid electrolyte compared to the conventional one. Indeed, the 


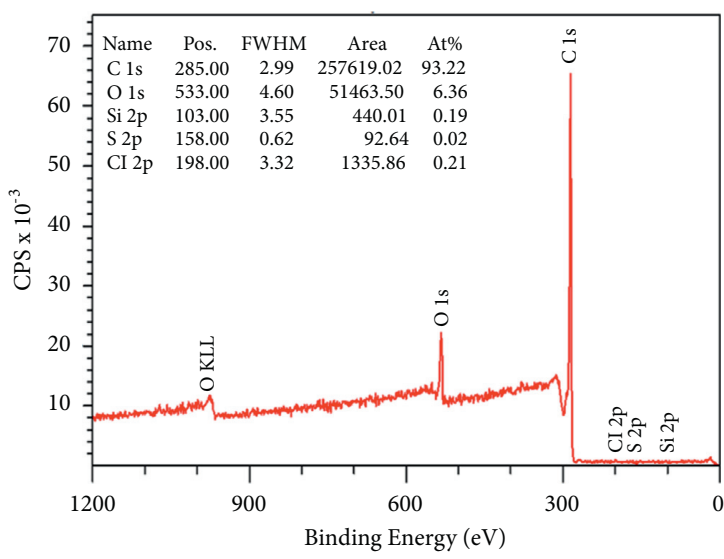

(a)

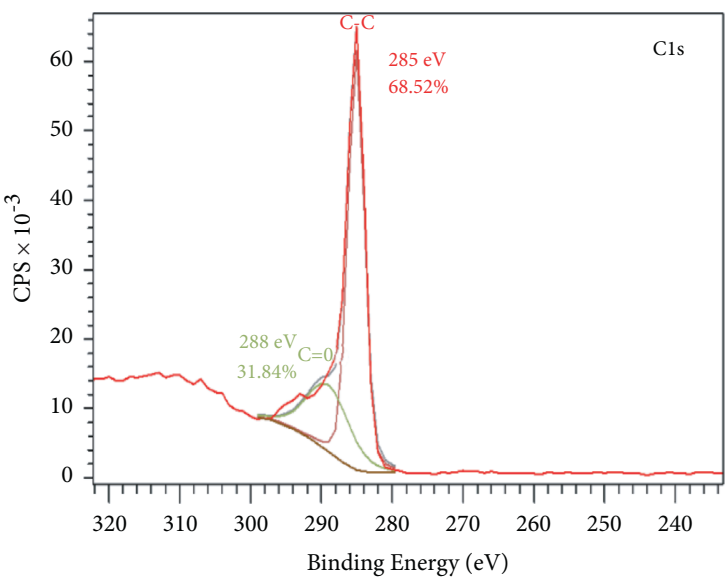

(b)

FIgURE 6: XPS spectra of activated carbon (AC). (a) Survey spectrum. (b) C 1s spectra.

TABLE 4: XPS elemental analysis (\% surface atomic composition).

\begin{tabular}{lcccc}
\hline Component & Binding energy $(\mathrm{eV})$ & Height & Area & \% surface atomic composition \\
\hline $\mathrm{C}$ & 285 & 9490.4 & 257619.0 & 93.22 \\
$\mathrm{Cl}$ & 198.0 & 67.4 & 1335.9 & 0.21 \\
$\mathrm{O}$ & 533 & 1005.8 & 51463.5 & 6.36 \\
$\mathrm{~S}$ & 158 & 24.9 & 92.6 & 0.02 \\
$\mathrm{Si}$ & 103 & 43.4 & 440.0 & 0.20 \\
\hline
\end{tabular}

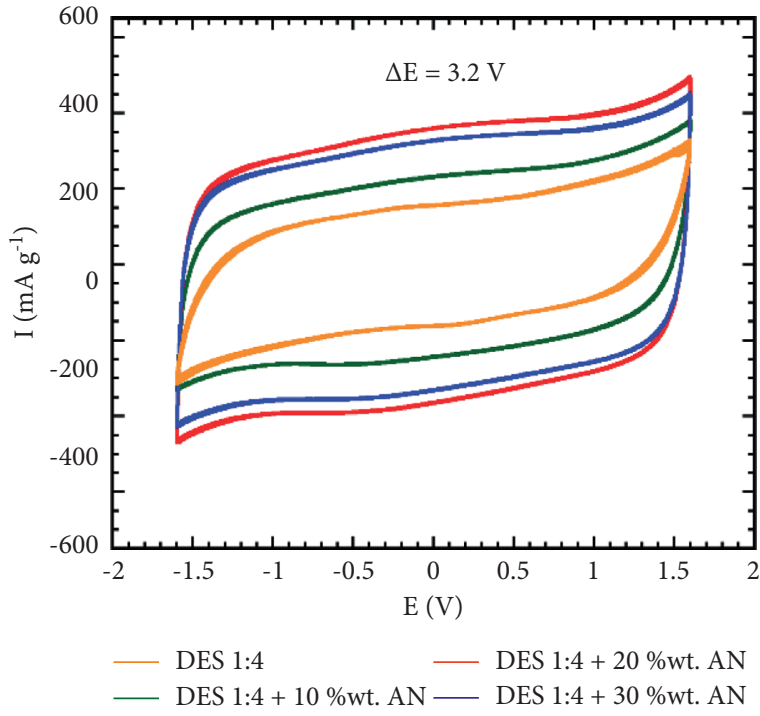

(a)

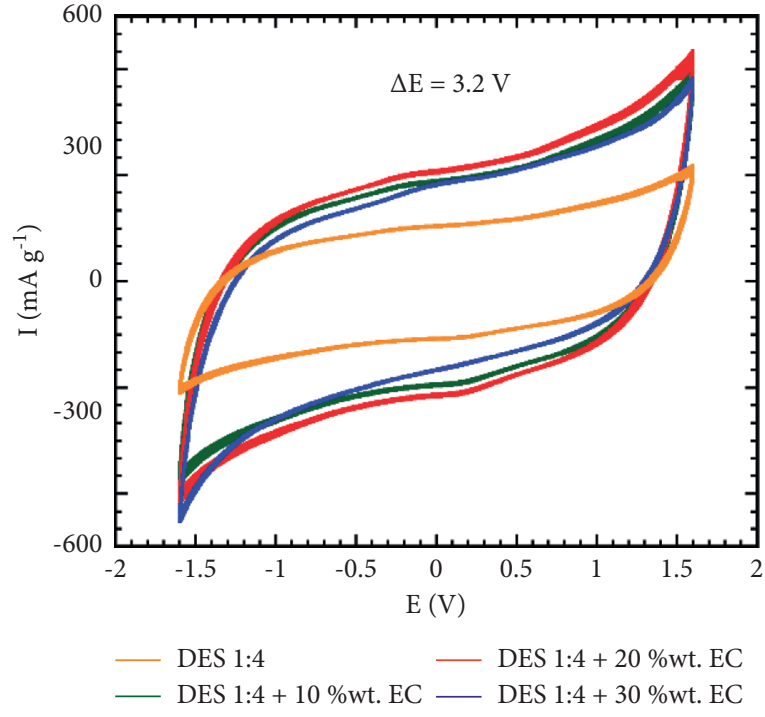

(b)

FIgURE 7: Continued. 


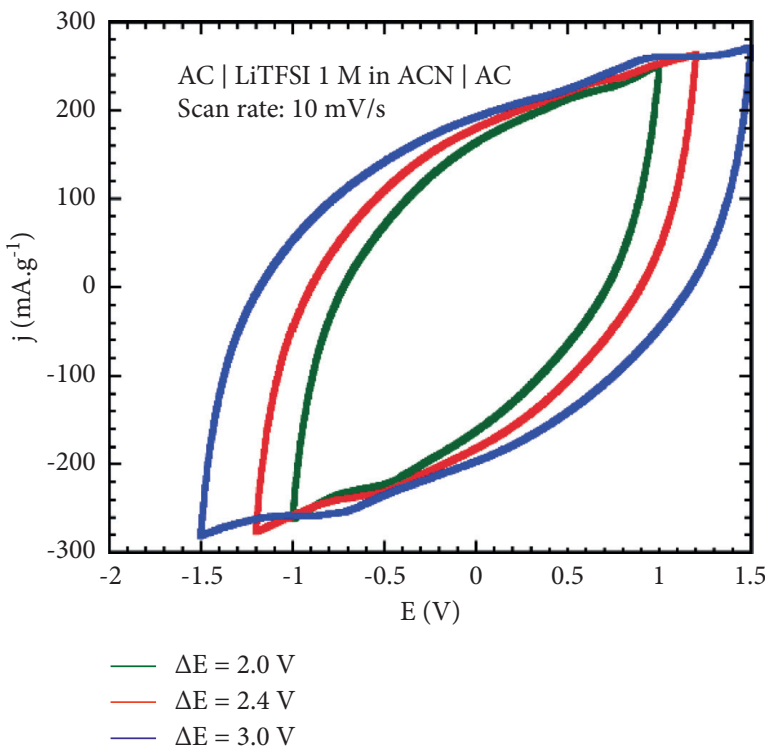

(c)

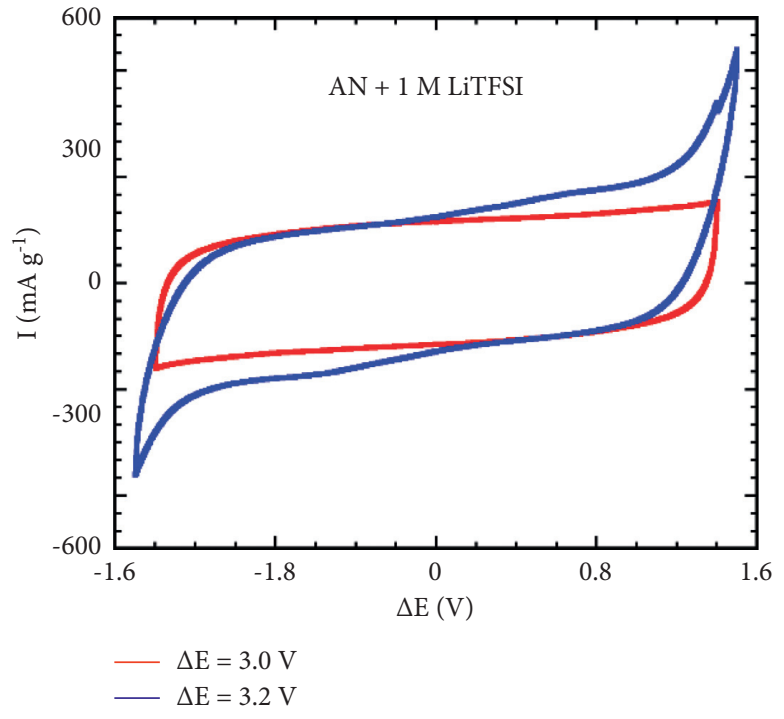

(d)

FIGURE 7: CV curves of supercapacitors using (a) DES 1:4+x\% wt. AN, (b) DES 1:4+x\% wt. AN in the potential window of $3.2 \mathrm{~V}$, (c) $\mathrm{AN}+1 \mathrm{M}$ TBABF4, and (d) AN $+1 \mathrm{M}$ LiTFSI at different potential windows $\left(v=10 \mathrm{mV} \cdot \mathrm{s}^{-1}\right)$.

TABLE 5: $Q_{\text {charge }} / Q_{\text {discharge }}$ and capacitance with different potential windows at $v=10 \mathrm{mV} \cdot \mathrm{s}^{-1}$.

\begin{tabular}{|c|c|c|c|c|c|c|}
\hline & \multirow[t]{2}{*}{ No. cycle } & \multicolumn{2}{|c|}{$\begin{array}{c}Q_{\text {charge }} / Q_{\text {discharge }} \\
(\%)\end{array}$} & \multicolumn{2}{|c|}{ Capacitance $\left(\mathrm{F} \cdot \mathrm{g}^{-1}\right)$} & \multirow[t]{2}{*}{ Average capacitance loss (\%) } \\
\hline & & $1^{\text {st }}$ & $100^{\text {th }}$ & $1^{\text {st }}$ & $100^{\text {th }}$ & \\
\hline \multirow{3}{*}{ DES $1: 4+10 \%$ wt. AN } & $\Delta E=2.8 \mathrm{~V}$ & 99.9 & 99.9 & 10.95 & 10.85 & 0.9 \\
\hline & $\Delta E=3.0 \mathrm{~V}$ & 99.9 & 99.9 & 11.29 & 10.90 & 3.4 \\
\hline & $\Delta E=3.2 \mathrm{~V}$ & 99.9 & 99.9 & 11.11 & 10.30 & 7.3 \\
\hline \multirow{3}{*}{ DES $1: 4+20 \%$ wt. AN } & $\Delta E=3.2 \mathrm{~V}$ & 99.9 & 99.9 & 15.23 & 15.11 & 0.8 \\
\hline & $\Delta E=3.4 \mathrm{~V}$ & 99.9 & 99.9 & 16.99 & 16.60 & 2.3 \\
\hline & $\Delta E=3.6 \mathrm{~V}$ & 99.9 & 99.9 & 17.18 & 15.55 & 9.5 \\
\hline \multirow{3}{*}{ DES $1: 4+30 \%$ wt. AN } & $\Delta E=3.2 \mathrm{~V}$ & 99.7 & 99.6 & 15.16 & 15.11 & 0.3 \\
\hline & $\Delta E=3.4 \mathrm{~V}$ & 99.8 & 99.8 & 16.64 & 15.88 & 4.6 \\
\hline & $\Delta E=3.6 \mathrm{~V}$ & 99.9 & 99.9 & 17.25 & 15.54 & 9.9 \\
\hline \multirow{3}{*}{ DES $1: 4+10 \%$ wt. EC } & $\Delta E=2.8 \mathrm{~V}$ & 99.9 & 99.9 & 12.18 & 12.02 & 1.3 \\
\hline & $\Delta E=3.0 \mathrm{~V}$ & 99.6 & 99.4 & 12.82 & 13.70 & - \\
\hline & $\Delta E=3.2 \mathrm{~V}$ & 99.6 & 99.9 & 14.56 & 15.22 & - \\
\hline \multirow{3}{*}{ DES $1: 4+20 \%$ wt. EC } & $\Delta E=2.8 \mathrm{~V}$ & 99.9 & 99.9 & 13.24 & 13.09 & 1.1 \\
\hline & $\Delta E=3.0 \mathrm{~V}$ & 99.7 & 99.9 & 14.11 & 14.83 & - \\
\hline & $\Delta E=3.2 \mathrm{~V}$ & 99.4 & 99.6 & 15.67 & 16.20 & - \\
\hline \multirow{3}{*}{ DES $1: 4+30 \%$ wt. EC } & $\Delta E=2.8 \mathrm{~V}$ & 99.8 & 98.6 & 11.24 & 10.94 & 2.7 \\
\hline & $\Delta E=3.0 \mathrm{~V}$ & 97.3 & 97.8 & 12.14 & 12.95 & - \\
\hline & $\Delta E=3.2 \mathrm{~V}$ & 97.2 & 96.5 & 14.03 & 14.60 & - \\
\hline
\end{tabular}

inner pores seem to hardly release the absorbed ions in the discharge process; thus, the occupied sites could not absorb the ions again leading to the decrease in discharge capacity during long cycling. The highest value of capacitance retention is considered as the highest adsorption ability of the ion on the electrode surface. However, when the adsorption reaches the saturation stage, the cell performance also declined quickly (roughly 66\% after 5000 cycles).

According to the equivalent circuit simulation, the impedance variations of each part of the EDLC with different cycle times in $1 \mathrm{~A} \cdot \mathrm{g}^{-1}$ are shown in Figure 10(c). The charge transfer resistance $\left(R_{c t}\right)$ of this system decreases along with the cycle number although they have relatively similar series resistance $\left(R_{i}\right)$. The charge transfer at the electrode/electrolyte interface only occurs fast whenever the ion absorption fully reaches. Up to 5000 cycles, the charge transfer had the lowest value indicating that the hybrid electrolyte based on DES requires more time to wet and adsorb onto the accessible surface of active material due to its high viscosity. Furthermore, the slow adsorption of ions is also revealed by the sloping of straight lines to the imaginary axis on the complex plane plots. As shown in inset of Figure 10(b), at the 

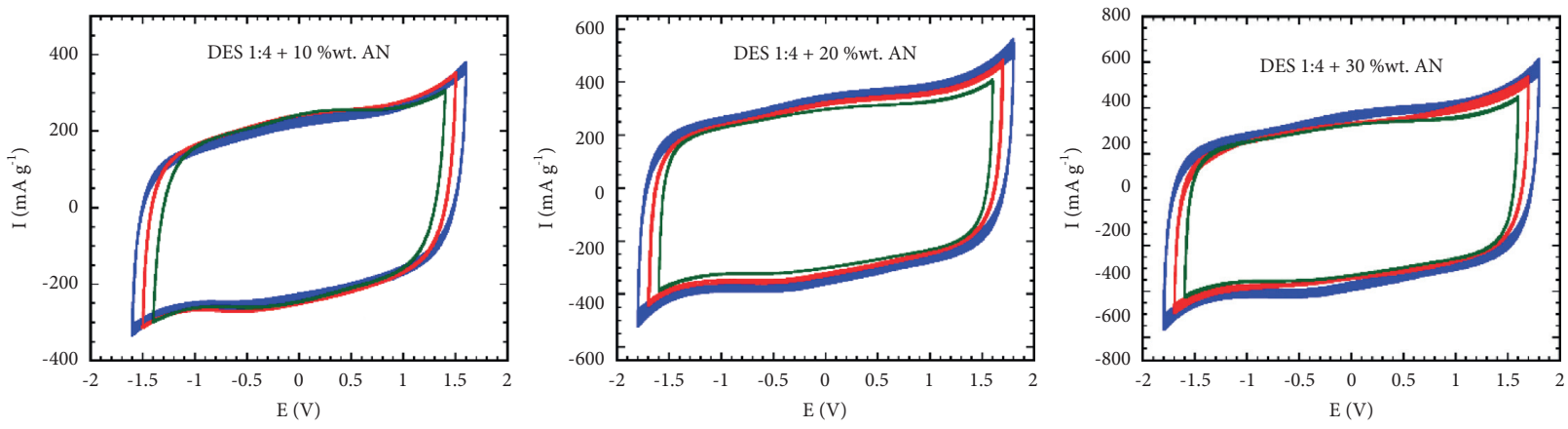

$$
\begin{aligned}
\Delta \mathrm{E} & =3.2 \mathrm{~V} \\
\Delta \mathrm{E} & =3.0 \mathrm{~V} \\
\Delta \mathrm{E} & =2.8 \mathrm{~V}
\end{aligned}
$$
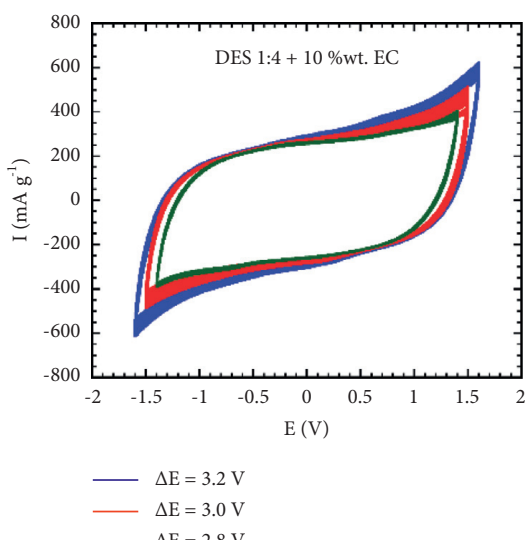

$$
\begin{aligned}
\Delta \mathrm{E} & =3.6 \mathrm{~V} \\
\Delta \mathrm{E} & =3.4 \mathrm{~V}
\end{aligned}
$$$$
\Delta \mathrm{E}=3.2 \mathrm{~V}
$$

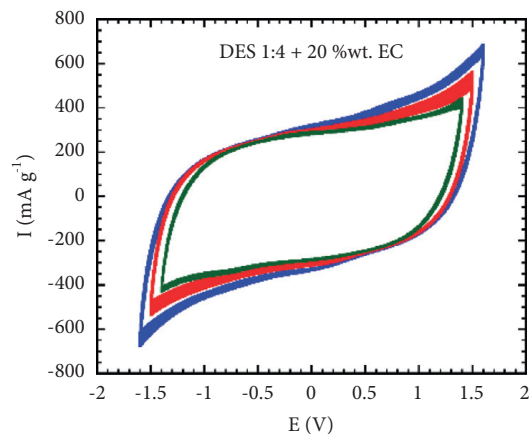

$\mathrm{E}(\mathrm{V})$

$$
\begin{aligned}
\Delta \mathrm{E} & =3.2 \mathrm{~V} \\
\Delta \mathrm{E} & =3.0 \mathrm{~V}
\end{aligned}
$$

$$
\begin{aligned}
\Delta \mathrm{E} & =3.6 \mathrm{~V} \\
\Delta \mathrm{E} & =3.4 \mathrm{~V} \\
\Delta \mathrm{E} & =3.2 \mathrm{~V}
\end{aligned}
$$

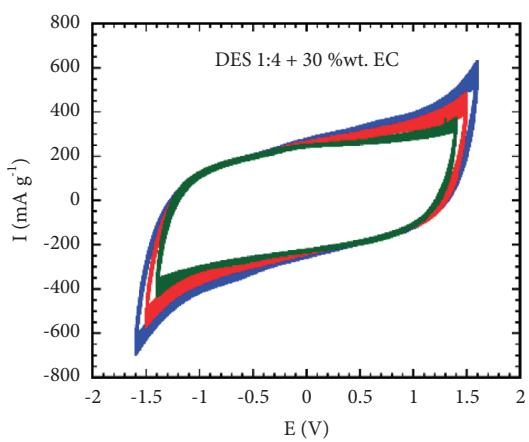

$$
\begin{aligned}
\Delta \mathrm{E} & =3.2 \mathrm{~V} \\
\Delta \mathrm{E} & =3.0 \mathrm{~V}
\end{aligned}
$$$$
\Delta \mathrm{E}=2.8 \mathrm{~V}
$$

FIgURE 8: The enlarged working voltage of ESs using various DES-based electrolytes $\left(v=10 \mathrm{mV} \cdot \mathrm{s}^{-1}\right)$. The scan was repeated 100 times for each operating voltage.

TABLE 6: Capacitance was calculated from GCPL cycling test at various scan rates.

\begin{tabular}{lcccr}
\hline & \multicolumn{5}{c}{$\mathrm{C}\left(\mathrm{F} \cdot \mathrm{g}^{-1}\right)$} \\
\hline I $\left(\mathrm{A} \cdot \mathrm{g}^{-1}\right)$ & 1 & 2 & 5 & 10 \\
\hline DES $1: 4+20 \%$ wt. AN & 15.6 & 13.2 & 9.3 & 6.0 \\
\hline DES $1: 4+30 \%$ wt. AN & 16.8 & 12.2 & 6.5 & 1.9 \\
\hline
\end{tabular}

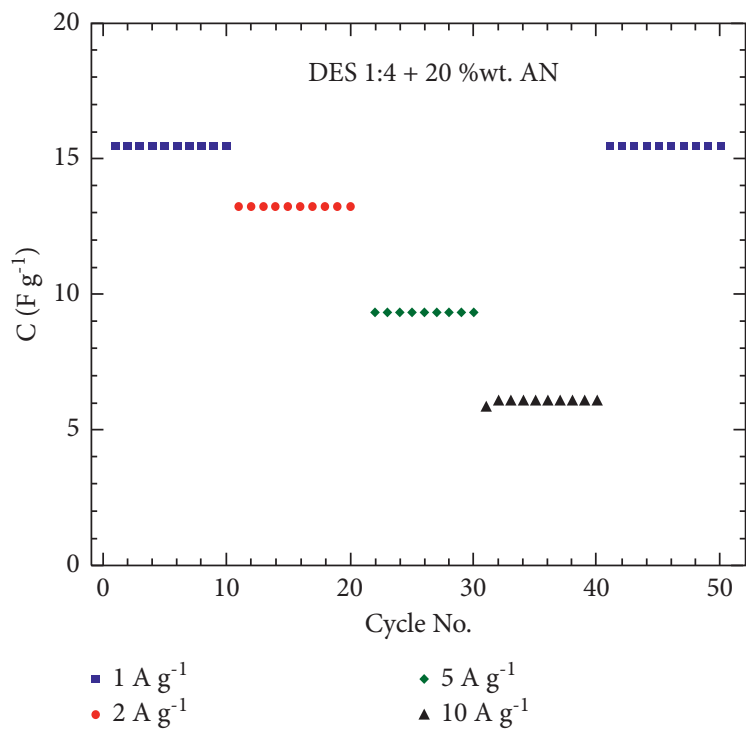

(a)

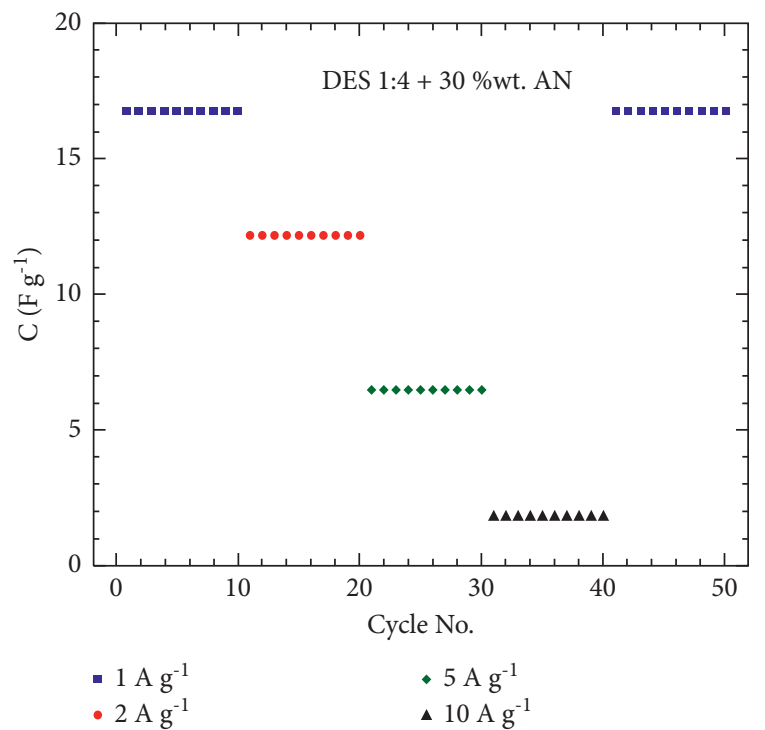

(b)

FIGURE 9: Specific capacitances at different current densities of (a) DES $1: 4+20 \%$ wt. AN and (b) DES $1: 4+30 \%$ wt. AN system. 

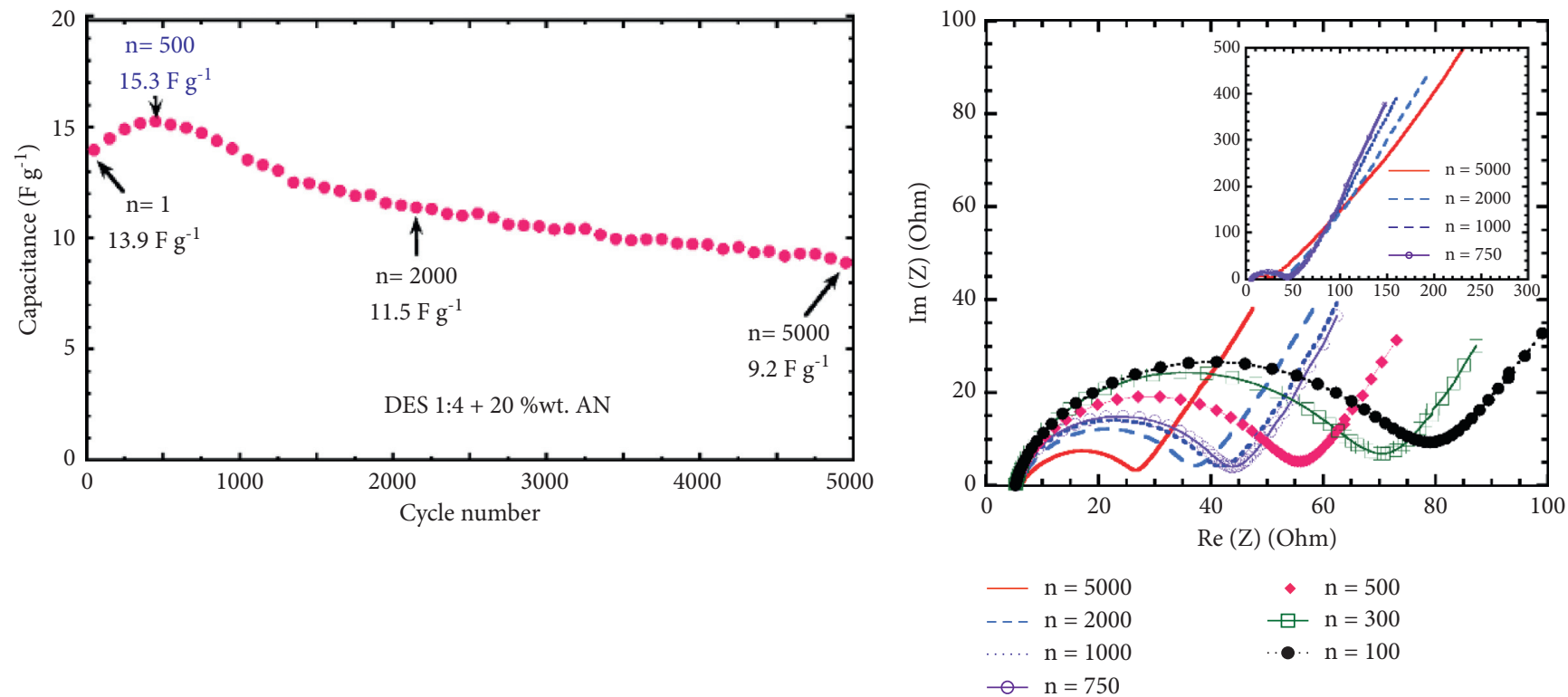

(a)

(b)

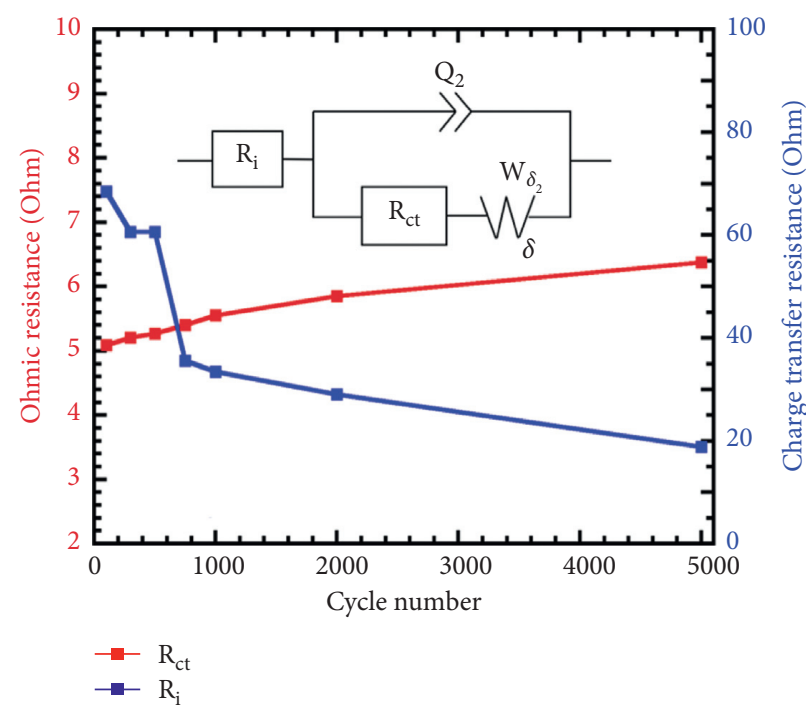

(c)

Figure 10: (a) Capacitance vs. cycle number of the DES $1: 4+20 \%$ wt. AN system at $\Delta E=3.4 \mathrm{~V}$ and $v=1 \mathrm{~A} \cdot \mathrm{g}^{-1}$. (b) Nyquist plots of the system containing $20 \%$ wt. AN after different charge/discharge cycles. (c) The charge transfer resistance $\left(R_{c t}\right)$, Ohmic resistance $\left(R_{i}\right)$ versus cycle number, and the equivalent circuit.

$750^{\text {th }}$ cycle, the curve is quite similar to the ideal plot of the supercapacitor with the least slope demonstrating a perfectly polarizable electrode. Therefore, the double-layer capacitance drastically drops after hundreds of cycles which is consistent with the cycling test (Figure 10(a)).

\section{Conclusions}

In comparison with the neat DES 1:4, DES-based electrolytes exhibited (i) a negligible impact on DES configuration with a low content of organic solvent $(<50 \% \mathrm{wt})$; (ii) relatively lower thermal stability confirmed by the decreasing the $1^{\text {st }}$ weight loss temperature and the slight increase of SET value; (iii) significantly lower viscosity $(14.28 \mathrm{mPa} \cdot \mathrm{s}, 2$ times lower than DES pure) and higher conductivity $\left(3.06 \mathrm{mS} \cdot \mathrm{cm}^{-1}\right)$; and (iv) wider electrochemical window whereas $20-30 \%$ wt. EC or AN (up to $3.4 \mathrm{~V}$ ) is the best concentration for enhancing the potential limits. Regarding the electrochemical performance, DES-AN systems revealed better charge propagation and good reversibility, while DESEC ones showed a seriously distorted rectangular shape. The use of DES 1:4+20-30\% wt. AN electrolyte-based supercapacitor could widen the operating potential window up to $3.4 \mathrm{~V}$, show good capacitance $15 \mathrm{~F} \cdot \mathrm{g}^{-1}$ at a rate of $1 \mathrm{~A} \cdot \mathrm{g}^{-1}$, remain around $95 \%$ after 100 cycles, and then decrease to $11.5 \mathrm{~F} \cdot \mathrm{g}^{-1}$ at the $2000^{\text {th }}$ cycle and $9.2 \mathrm{~F}^{-1} \mathrm{~g}^{-1}$ at the $5000^{\text {th }}$ cycle and good charge-discharge durability $(>80 \%$ after 2000 cycles). Especially, the EDLC using DES 1:4+20\% wt. AN 
shows good rate capacitance $\left(13.2 \mathrm{~F} \cdot \mathrm{g}^{-1}\right.$ at $2 \mathrm{~A} \cdot \mathrm{g}^{-1}$, remaining $6 \mathrm{~F} \cdot \mathrm{g}^{-1}$ at $\left.10 \mathrm{~A} \cdot \mathrm{g}^{-1}\right)$. Unexpectedly, the long cycling capacitance, as well as cyclability of these systems, is constrained by the low ion adsorption rate and weak electrolyte transportability.

\section{Data Availability}

The data used to support the findings of this study are available from the corresponding author upon request.

\section{Conflicts of Interest}

The authors declare that they have no conflicts of interest.

\section{Acknowledgments}

This research was funded by the Vietnam National University of Ho Chi Minh City (VNU-HCM) under grant code B2019-18-06. The authors Tran Van Man and Tran Thi Thuy Kieu also thank the Center of Excellence for Innovation in Chemistry (PERCH-CIC), Mahidol University, and Professor Pasit Pakawatparunut for the support during their time in Mahidol University for the physico-chemical measurements.

\section{References}

[1] J. P. Holdren, "Energy and sustainability," Science, vol. 315, no. 5813, p. 737, 2007.

[2] H. Michel, "Temperature and dynamics problems of ultracapacitors in stationary and mobile applications," Journal of Power Sources, vol. 154, no. 2, pp. 556-560, 2006.

[3] Y. Korenblit, A. Kajdos, W. C. West et al., "In situ studies of ion transport in microporous supercapacitor electrodes at ultralow temperatures," Advanced Functional Materials, vol. 22, no. 8, pp. 1655-1662, 2012.

[4] J. P. Matthews, A. J. Smith, and I. D. Smith, "A remote unmanned ELF/VLF goniometer receiver in Antarctica," Planetary and Space Science, vol. 27, no. 11, pp. 1391-1401, 1979.

[5] P. Simon and Y. Gogotsi, "Materials for electrochemical capacitors," Nature Materials, vol. 7, pp. 845-854, 2008.

[6] G. Zhao, C. Chen, D. Yu et al., "One-step production of ONS co-doped three-dimensional hierarchical porous carbons for high-performance supercapacitors," Nano Energy, vol. 47, pp. 547-555, 2018.

[7] Z. Bi, Q. Kong, Y. Cao et al., "Biomass-derived porous carbon materials with different dimensions for supercapacitor electrodes: a review," Journal of Materials Chemistry A, vol. 7, no. 27, pp. 16028-16045, 2019.

[8] J. Garche, C. K. Dyer, P. T. Moseley, Z. Ogumi, D. A. J. Rand, and B. Scrosati, Encyclopedia of Electrochemical Power Sources, Newnes, London, UK, 2013.

[9] S. Najib and E. Erdem, "Current progress achieved in novel materials for supercapacitor electrodes: mini review," Nanoscale Advances, vol. 1, no. 8, pp. 2817-2827, 2019.

[10] C. Lamiel and J. J. Shim, "3D hierarchical mesoporous $\mathrm{NiCo}_{2} \mathrm{~S}_{4} @ \mathrm{Ni}(\mathrm{OH})_{2}$ core-shell nanosheet arrays for high performance supercapacitors," New Journal of Chemistry, vol. 40, pp. 4810-4817, 2016.

[11] N. Joseph, P. Muhammed Shafi, and A. Chandra Bose, "Metallic 1T- $\mathrm{MoS}_{2}$ with defect induced additional active edges for high performance supercapacitor application," New Journal of Chemistry, vol. 42, no. 14, pp. 12082-12090, 2018.

[12] D. P. Dubal and R. Holze, "A successive ionic layer adsorption and reaction (SILAR) method to induce Mn3O4nanospots on CNTs for supercapacitors," New Journal of Chemistry, vol. 37, no. 2, pp. 403-408, 2013.

[13] S. Hussain, A. J. Khan, M. Arshad et al., "Charge storage in binder-free 2D-hexagonal CoMoO4 nanosheets as a redox active material for pseudocapacitors," Ceramics International, vol. 47, no. 6, pp. 8659-8667, 2021.

[14] M. Sufyan Javed, M. Imran, M. A. Assiri et al., "One-step synthesis of carbon incorporated 3D $\mathrm{MnO} 2$ nanorods as a highly efficient electrode material for pseudocapacitors," Materials Letters, vol. 295, Article ID 129838, 2021.

[15] J. Xi, M. S. Javed, S. Asim et al., "High-performance flexible supercapatteries enabled by binder-free two-dimensional mesoporous ultrathin nickel-ferrite nanosheets," Materials Chemistry Frontiers, vol. 5, no. 8, pp. 3436-3447, 2021.

[16] D. Zhou, D. Shanmukaraj, A. Tkacheva, M. Armand, and G. Wang, "Polymer electrolytes for lithium-based batteries: advances and prospects," Chem, vol. 5, no. 9, pp. 2326-2352, 2019.

[17] X. Fan, L. Chen, O. Borodin et al., "Non-flammable electrolyte enables Li-metal batteries with aggressive cathode chemistries," Nature Nanotechnology, vol. 13, 2018.

[18] N. W. Li, Y. X. Yin, J. Y. Li, C. H. Zhang, and Y. G. Guo, "Passivation of lithium metal anode via hybrid ionic liquid electrolyte toward stable Li plating/stripping," Advanced Science, vol. 4, no. 2, Article ID 1600400, 2017.

[19] W. Zaidi, A. Boisset, J. Jacquemin, L. Timperman, and M. Anouti, "Deep eutectic solvents based on N-methylacetamide and a lithium salt as electrolytes at elevated temperature for activated carbon-based supercapacitors," The Journal of Physical Chemistry C, vol. 118, no. 8, pp. 4033-4042, 2014.

[20] Y. Chen and T. Mu, "Application of deep eutectic solvents in biomass pretreatment and conversion," Green Energy \& Environment, vol. 4, no. 2, pp. 95-115, 2019.

[21] Q. Zhang, K. de Oliveira Vigier, S. Royer, and F. Jérôme, "Deep eutectic solvents: syntheses, properties and applications," Chemical Society Reviews, vol. 41, no. 21, pp. 7108-7146, 2012.

[22] L. T. M. Le, T. D. Vo, K. H. P. Ngo et al., "Mixing ionic liquids and ethylene carbonate as safe electrolytes for lithium-ion batteries," Journal of Molecular Liquids, vol. 271, pp. 769-777, 2018.

[23] K. T. T. Tran, L. T. M. Le, A. L. B. Tran et al., "New deep eutectic solvents based on ethylene glycol-LiTFSI and their application as an electrolyte in electrochemical double layer capacitor (EDLC)," Journal of Molecular Liquids, vol. 320, Article ID 114495, 2020.

[24] T. T. A. Dinh, T. T. K. Huynh, L. T. M. Le et al., "Deep eutectic solvent based on lithium bis[(trifluoromethyl)sulfonyl] imide (LiTFSI) and 2,2,2-trifluoroacetamide (TFA) as a promising electrolyte for a high voltage lithium-ion battery with a $\mathrm{LiMn}_{2} \mathrm{O}_{4}$ cathode," ACS Omega, vol. 5, no. 37, pp. 23843-23853, 2020.

[25] I. Spectra, M. Vibrations, and E. Glycol, "Infrared spectra glycol and molecular and deuterated vibrations of ethylene derivatives," Bulletin of the Chemical Society of Japan, vol. 40, pp. 85-94, 1967.

[26] A. Arbor, "Effect of hydrogen bonding on the deformation frequencies of the hydroxyl group in alcohols," Journal of Chemical Physics, vol. 24, p. 559, 1956. 
[27] E. M. Kosower, G. Markovich, and G. Borz, "Thin-film infrared spectroscopy of acetonitrile," ChemPhysChem, vol. 8, no. 17, pp. 2513-2519, 2007.

[28] E. A. Guggenheim, "The theoretical basis of raoult's law," Transactions of the Faraday Society, vol. 33, pp. 151-156, 1937.

[29] S. Hess, M. Wohlfahrt-mehrens, and M. Wachtler, "Flash point and self-extinguishing time measurements," Journal of the Electrochemical Society, vol. 162, no. 2, pp. A3084-A3097, 2015.

[30] C. Arbizzani, G. Gabrielli, and M. Mastragostino, “Thermal stability and flammability of electrolytes for lithium-ion batteries," Journal of Power Sources, vol. 196, no. 10, pp. 4801-4805, 2011.

[31] G. G. Eshetu, S. Grugeon, H. Kim et al., "Comprehensive insights into the reactivity of electrolytes based on sodium ions," ChemSusChem, vol. 9, no. 5, pp. 462-471, 2016.

[32] M. Vidal, W. J. Rogers, J. C. Holste, and M. S. Mannan, “A review of estimation methods for flash points and flammability limits," Process Safety Progress, vol. 23, no. 1, pp. 47-55, 2004.

[33] M. S. Ding, K. Xu, and T. R. Jow, "Liquid-solid phase diagrams of binary carbonates for lithium batteries," Journal of the Electrochemical Society, vol. 147, no. 5, p. 1688, 2000.

[34] I. N. Daniels, Z. Wang, and B. B. Laird, "Dielectric properties of organic solvents in an electric field," The Journal of Physical Chemistry C, vol. 121, no. 2, pp. 1025-1031, 2017.

[35] J. F. Moulder, W. F. Stickle, P. E. Sobol, and K. D. Bomben, Handbook of X-ray Photoelectron Spectroscopy, J. Chastain, R. C. King, and Jr, Eds., p. 248, Physical Electronics Ins., Chanhassen, MN, USA, 1992.

[36] Z. H. Huang, T. Y. Liu, Y. Song, Y. Li, and X. X. Liu, "Balancing the electrical double layer capacitance and pseudocapacitance of hetero-atom doped carbon," Nanoscale, vol. 9, no. 35, pp. 13119-13127, 2017. 